\title{
Conhecendo Ciudad del Este: O Outro Lado da Fronteira ${ }^{1}$
}

\author{
Conociendo Ciudad del Este: El Otro Lado de la Frontera
}

\author{
Knowing Ciudad del Este: The Other Side of the Border
}

\author{
Roberto Rigaud Navega Costa ${ }^{2}$
}

\begin{abstract}
Resumo
O presente trabalho tem como objetivo apresentar ao leitor um relato de experiência, a saber, o das percepções obtidas por alguém que passando pela Ponte da Amizade chegue à Ciudad del Este, no Paraguai. A descrição pretende dar uma ideia aproximada da paisagem esculpida pela sociedade local, em sua articulação com os turistas e os sacoleiros, e como este comércio influenciou na formação, arranjo e desenvolvimento da parte comercial da cidade. Como o texto deixa transparecer, fomos inspirados pelos trabalhos de Geografia Regional de Paul Vidal de La Blache, que ao tentar descrever a paisagem de uma determinada região fazia um quadro vívido do que encontraríamos em tal local. Passamos assim, a descrever a topografia, composição da população, táticas de aquisição de clientes/compradores por parte dos comerciantes, a arquitetura local, o arranjo das vias e dos edifícios, visando a estabelecer o quadro geral mais bem explicado, tendo como limitadores o próprio espaço do texto e sua aplicação à comunidade acadêmica.
\end{abstract}

Palavras-Chave: Ciudad del Este; Descrição; Paisagem; Fronteira.

\section{Resumen}

El presente trabajo tiene como objetivo presentar al lector un relato de experiencia, a saber, el de las percepciones obtenidas por alguien que pasa por el Puente de la Amistad llegue a la Ciudad del Este, en Paraguay. La descripción pretende dar una idea aproximada del paisaje esculpido por la sociedad local, en su articulación con los turistas y los sacoleros, y cómo este comercio influenció en la formación, arreglo y desarrollo de la parte comercial de la ciudad. Como el texto deja traslujo, fuimos inspirados por los trabajos de Geografía Regional de Paul Vidal de La Blache, que al tratar de describir el paisaje de una determinada región hacía un cuadro vívido de lo que encontraríamos en tal local. Pasamos así a describir la topografía, composición de la población, tácticas de adquisición de clientes/compradores por parte de los comerciantes, la arquitectura local, el arreglo de las vías y de los edificios, con el fin de establecer el marco general más bien explicado, teniendo como limitadores el propio espacio del texto y su aplicación a la comunidad académica.

Palabras claves: Ciudad del Este; Descripción; Paisaje; Frontera.

\begin{abstract}
This paper aims to present to the reader an experience report, namely, the perceptions obtained by someone passing through the Friendship Bridge (Ponte da Amizade) arriving in Ciudad del Este, Paraguay. The description intends to give a rough idea of the landscape sculpted by the local society, in its articulation with the tourists and the wagons, and how this commerce influenced in the formation, arrangement and development of the commercial part of the city. As the text makes clear, we were inspired by the works of Paul Vidal de La Blache's Regional Geography, who in trying to describe the landscape of a particular region made a vivid picture of what we would find in such a place. Thus, we describe the topography, population composition, tactics of acquisition of customers / buyers by traders, the local architecture, the arrangement of roads and buildings,
\end{abstract}

\footnotetext{
${ }^{1}$ Artigo apresentado durante o I Congresso Internacional Online de Estudos sobre Culturas - \#Culturas, realizado de forma online, em outubro de 2019.

2 Mestrando no PPG em Sociedade, Cultura e Fronteiras, Unioeste; Foz do Iguaçu, Paraná, Brasil; ramosnavega@gmail.com.
} 
aiming to establish the best-explained general framework, having as limitation the own space of the text and its application to the academic community.

Keywords: Ciudad del Este; Description; Landscape; Border.

\section{Introdução}

Diariamente, de segunda a sábado, milhares de pessoas chegam à Foz do Iguaçu com um único intuito: fazer compras no Paraguai. Elas passam pela Ponte da Amizade, e chegam em Ciudad del Este, prontas para adquirir uma grande quantidade de bens para que possam revender em suas cidades de origem. Tal prática já ocorre a décadas, e mesmo com o combate ao descaminho a atividade dos chamados sacoleiros varia, mas nunca se esgota.

O presente trabalho visa dar uma imagem aproximada do arranjo territorial de Ciudad del Este, em sua parte de comércio voltada aos estrangeiros, descrevendo a disposição dos eixos de tráfego viário, das edificações, das lojas, de comerciantes e dos pontos preferidos de compra de mercadorias por parte dos sacoleiros (importadores informais de produtos industrializados, provenientes em sua maioria da China).

Tal descrição visa informar como está estruturada esta parte da cidade e quais são as impressões que os sacoleiros recebem quando passam de seu território nacional para um outro país, onde a língua, o povo, a cultura, o dinheiro, e principalmente as leis são diferentes. A experiência de cruzar uma fronteira pode ser exótica para uns, mas traumática para outros tantos. Há riscos associados às atividades no circuito sacoleiro (CARDIN, 2006), e parte deles no Paraguai.

\section{Metodologia}

O presente estudo se utilizará das ferramentas conceituais próprias das pesquisas de campo do tipo qualitativas. Não precisaremos de levantar dados quantitativos, nem sequer tratar dados deste tipo. Caso haja a necessidade de citar números, eles servirão apenas como lastro às explicações gerais, e virão de fontes externas à pesquisa. Assim, concordamos com Minayo (2002, p. 15) que afirma que nas ciências sociais o natural é a pesquisa qualitativa, de acordo com a natureza de seu objeto.

Para tal pesquisa qualitativa nos utilizaremos de procedimentos metodológicos o deslocamento pelas ruas do microcentro de Ciudad del Este, indo de rua em rua, buscando identificar as características locais, anotando cada fato que nos chame a atenção. Assim, as 
técnicas aplicadas no campo foram bem simples, caneta, papel e bastante disposição para caminhar pela área comercial desta cidade.

Como atividade humana, a pesquisa pode ser entendida como um procedimento sistemático, racional, que visa dar respostas a problemas predefinidos. Tal atividade desenrola-se em várias etapas, que vão da apresentação do problema de pesquisa até a formulação e discussão de resultados alcançados (Gil, 2007, p. 17).

Esta pesquisa também tem como característica o fato de poder ser classificada como sendo descritiva. A pesquisa exploratória visa proporcionar maior familiaridade com o problema proposto, através de levantamento bibliográfico, de entrevistas (se forem necessárias) com pessoas que têm informações relevantes, e apresentação de exemplos que esclareçam o problema em direção à elucidação do mesmo (GIL, 2007).

Já a característica descritiva da pesquisa tenta apresentar fatos e fenômenos relevantes de determinada porção da realidade (TRIVIÑOS, 1987). Esta espécie de pesquisa tem o problema associado de depender do viés do pesquisador, que pode ver e descrever o que lhe interesse e deixar de lado um conjunto considerável de informações, que para os demais observadores poderia ser altamente relevante. Mesmo assim é uma ferramenta a mais.

A pesquisa classificável como sendo explicativa tem como característica principal o fato de se preocupar em identificar fatores que influem na ocorrência do fenômeno apontado pelo problema de pesquisa. A partir dos resultados obtidos pode-se tentar criar uma explicação do porquê o objeto de pesquisa é e se comporta de tal ou tal forma. A descrição apresentada acima serve de fonte para as explicações subsequentes (Gil, 2007).

\section{Problema de Pesquisa}

Seguimos a pesquisa inspirados no método descritivo de Paul Vidal de La Blache (1913), que em sua Geografia Regional pretendia descrever a paisagem do local estudado, a fim de dar ao leitor uma visão de conjunto, não só a descrição física, humana, econômica, etc. Assim, queremos fazer o mesmo em relação à parte comercial de Ciudad del Este, destinada ao atendimento aos turistas e principalmente aos sacoleiros.

Paul Vidal de La Blache propõe à Geografia um novo método, utilizando-se de um ponto de vista funcional e histórico. Assim, haveria uma relação entre homem e o meio que o circunda que se daria de forma harmônica e recíproca, onde cada um sofreria influência do outro. Mesmo recebendo influências do ambiente ao qual está vinculado, o homem também 
age como se fosse mais um dos fatores geográficos, onde um e outro se transformariam reciprocamente (FABRÍCIO e VITTE, 2011).

Nossa pretensão é dar este panorama geral da paisagem, e das relações espaciais que são passíveis de obtenção através do olhar do pesquisador, para daí podermos traçar um perfil apropriado do arranjo territorial e de seu uso, tanto por parte dos Paraguaios, quanto da parte dos demais povos, de várias origens, associados ao comércio descrito acima e à movimentação do chamado Circuito Sacoleiro (CARDIN, 2010).

\section{Uma Cidade Comercial}

Ciudad del Este foi inaugurada com o nome de Puerto Presidente Stroessner em 1957 (TISSIANO, 2018), na margem do Rio Paraná oposta a Foz do Iguaçu. A ideia era de aproveitar-se do ponto de escoamento da produção agrícola do Paraguai e instalar um polo de revenda de produtos industrializados importados (atualmente principalmente da China). O plano deu certo e esta parte da fronteira é a mais movimentada dentre todas as fronteiras do Brasil.

A ligação entre as duas cidades passou a poder ser feita sem a utilização do rio em 1965, com a inauguração da Ponte da Amizade, que facilitou o contato entre os países, e facilitou também a fiscalização alfandegária por parte do fisco dos dois países, o que era muito mais precário quando o Rio Paraná era a única opção de passagem para produtos e pessoas. A ponte aproximou as cidades e dificultou o trabalho dos sacoleiros.

Quando o sacoleiro, ou o turista, chega pela ponte à Ciudad del Este ele encontra a aduana paraguaia, e dependendo do horário ele verá depositadas ao chão, ladeando as pistas de tráfego de automóveis, as apreensões de alimentos feitas pelos fiscais daquele país. Como viver na fronteira pode significar viver da fronteira (COLOGNESE e CARDIN, 2014, p. 72), os moradores daquela cidade fazem compras de alimentos no lado brasileiro, pois há diferenças de cotações e preços.

Os fiscais de coletes padronizados têm o apoio de militares armados com fardas camufladas, que muitas vezes fazem o papel de parar e revistar os veículos que vêm do Brasil. Assim, carros, caminhões, vans e ônibus (de linha normal ou de turismo) passam pela fiscalização, e ao largo passam os pedestres, que em sendo sacoleiros, enxergam em Ciudad del Este seu Eldorado, onde poderão comprar itens comercializáveis no Brasil a preços mais em conta, e poderão auferir lucro com a atividade do descaminho. 
Muitos caminhões viram à direita, antes da aduana, para passar numa espécie de porto seco próprio para eles. Os demais acessam a cidade pela aduana mesmo. A esquerda de quem chega foi construído o Shopping del Este para se aproveitar da localização privilegiada. Ele tem certo luxo em relação aos demais, com exceção do Shopping Paris, recém-inaugurado, e da loja Sax. Suas lojas são mais voltadas ao turista-turista (RABOSSI, 2004, p. 54) do que aos sacoleiros, sendo seus preços altos para estes.

Saindo da aduana temos o eixo principal da cidade, que a corta em duas, sendo que as lojas mais atraentes aos sacoleiros se encontram do lado esquerdo, o mesmo que vem passando por uma revitalização considerável, com filiais das lojas mais famosas, como Mega Eletrônicos, Pionner e Cellshop. A loja de eletrônicos mais bem-conceituada do lado direito é a Madrid Center.

A topografia do terreno é bem irregular, pois aparenta que tanto Foz do Iguaçu, quanto Ciudad del Este foram instaladas às margens de um rio encaixado numa falha geológica que escalonou o terreno, criando ondas desde a barranca do rio até os limites das duas cidades. Assim, andar por esta parte da cidade é bem cansativo, e em dias de chuva fica-se vermelho de barro, o solo chamado "terra roxa", típico de origem de derramamento basáltico.

Cercando os pedestres podemos ver os distribuidores de panfletos, os mesmos que te seguem, e tentam te levar a uma loja específica, caso você pegue um dos panfletos. Estes trabalhadores informais recebem um pagamento por cada pessoa que levam à loja que os interessa. É uma forma de conseguir mais clientes para as lojas menores, pois as grandes lojas de eletrônicos e afins não precisam deste tipo de expediente.

Há no eixo principal uma rotatória (rotunda, como chamam no Paraguai), que distribui o trânsito para um eixo ortogonal, que distribui o trânsito à direita e à esquerda. Parece ter havido uma intenção de fazer uma ordenação em tipo xadrez, mas a topografia acabou deformando o traçado, e nos limites da área comercial já se perdeu o traçado retilíneo e vemos curvas e interrupções de ruas, que sobem e descem sem dar conta do desenho.

Há grandes blocos de construção, que são chamados de Shoppings, sendo estes bem diferentes do modelo tradicional do Brasil, pois parecem mal-acabados e entulhados de lojas mal arrumadas. Este perfil está mudando com a implantação de um novo layout, seguindo o modelo brasileiro, muito bem-acabadas e com um certo luxo. Mas em sua maioria ainda encontramos exemplos como o Lai-Lai e o Jebai, complexos de lojas no estilo de boxes de venda. 
Para economizar nos custos de aluguel as lojas têm sua área de vendas próximo do térreo, e com sua entrega nos andares acima, assim como sua área de teste, assistência técnica e garantia.

Quanto à composição dos proprietários de comércios em Ciudad del Este, podemos observar uma grande quantidade de imigrantes de origem síria e libanesa, seguidos por chineses, coreanos e muitos brasileiros. Os paraguaios figuram mais como funcionários, geralmente vendedores e pessoal de apoio, como estoquistas, entregadores, etc. Apenas as lojas menores apresentam donos paraguaios, mas há muitos deles entre os mesiteros (uma espécie de camelôs, cf. RABOSSI, 2004).

O ritmo da cidade nesta área comercial é bem intenso, com o constante vai e vem de compradores, mototaxistas, taxistas, motoristas de vans, carregadores, todos disputando um "patron" para poderem receber reais em troca de seus serviços de transporte. O assédio a sacoleiros e a turistas é intenso nas ruas, e o trânsito fica muito lento em certos momentos, fazendo das vias de tráfego uma fonte grande de estresse, perdendo apenas para a temida passagem pela aduana brasileira, com seus fiscais prontos do outro lado da ponte.

\section{Conclusões}

Apresentamos acima uma visão geral que um sacoleiro, ou turista, teria ao chegar em Ciudad del Este atravessando a Ponte da Amizade. Este foi um relato retirado de nossas experiências em campo, usando um olhar de atenta curiosidade para vermos tanto o comum, que poderíamos encontrar nas cidades brasileiras, quanto para o incomum, o que só encontraríamos nesta cidade paraguaia, o que a tornaria única.

Assinalamos que deixamos de fora um outro conceito de Paul Vidal de La Blache, o de modos de vida, já que gostaríamos de um relato de experiência um pouco mais superficial, sem entrarmos em considerações que deixariam o texto mais longo e pesado neste contexto de pesquisa. No entanto, o campo está aberto para que possamos em breve utilizarmos tal conceito, fazendo com que mais informações possamos ter deste espaço urbano tão rico.

Pudemos concluir que sua existência, como polo de reexportação de produtos industrializados, provenientes majoritariamente do oriente (principalmente China), se deve ao atendimento das carências do mercado brasileiro, que tem seus preços excessivamente altos e abre margem para a ocorrência, na faixa de fronteira, para o surgimento, manutenção e expansão deste tipo de entreposto. 
Se formos nos utilizar do conceito de La Blache de gênero de vida e tentássemos aplicar diretamente ao caso de Ciudad del Este teríamos dificuldades, já que esta cidade está mais voltada para atender às necessidades dos consumidores brasileiros do que em se integrar a uma função voltada para as demandas internas do Paraguai. A função de polo reexportador de produtos industrializados demonstra que a cidade em questão é mais ligada ao Brasil que a seu próprio Estado regulador. Mas, só o fato de podermos contar com o ponto de vista oriundo dos conceitos deste autor já nos dá mais ferramentas úteis de análise do meio geográfico e demonstra a versatilidade que a ciência ganha ao levar em conta uma contribuição tão distante no tempo, mas tão relevante em nossos dias.

Assim, Ciudad del Este se moldou às necessidades de mercado e virou sua face mais comercial, de concreto armado e vidraças espelhadas, para o Brasil, voltando-se de costas ao Paraguai, constituindo-se como um importante nó (CORRÊA, 1989) de uma rede internacional de comércio, e como passagem de um gigantesco fluxo de pessoas, bens e capitais, legais ou ilegais, por uma ponte que se diz amistosa, mas que abriga tensões variadas. O que pode vir a ser um excelente campo de investigações futuras.

\section{Referências}

CARDIN. Eric Gustavo. A Expansão Do Capital E As Dinâmicas Da Fronteira. Tese (Doutorado em Sociologia). Araraquara: UNESP, 2010.

Sacoleiros e Laranjas na Tríplice Fronteira: uma análise da precarização do trabalho no capitalismo contemporâneo. Dissertação (Mestrado em Sociologia). Araraquara: UNESP, 2006.

COLOGNESE, Silvio Antônio; CARDIN, Eric Gustavo. As Ciências Sociais nas Fronteiras: Teorias e Metodologias de Pesquisa. Cascavel: JB, 2014.

CORRÊA, Roberto Lobato. A Rede Urbana. São Paulo: Ática, 1989.

FABRÍCIO, Deyse Cristina Brito; VITTE, Antonio Carlos. Paul Vidal de La Blache e a Geografia Francesa: do Contexto Histórico às Monografias Urbanas. Cordis. História, Arte e Cidades, n. 6, jan./jun. pp. 301-332, 2011. Disponível em: https://revistas.pucsp.br/cordis/ article/view/10302/7691. Acesso em 16 set. 2019. 
GIL, A. C. Métodos e técnicas de pesquisa social. 4. ed. São Paulo: Atlas, 1994.

Como elaborar projetos de pesquisa. 4. ed. São Paulo: Atlas, 2007.

La Blache, Paul Vidal de. Transcrito dos Annales De Géographie, 22 (124): 289·299, 1913.

Titulo do original: "Descaractères distinctifs de la Géographie". Tradução de Odete Sandrini Mayer.

MINAYO, Maria Cecília de Souza. Teoria, Método e Criatividade. Petrópolis. $21^{\mathrm{a}}$ edição. Coleção Pesquisa Social. Ed Vozes. 2002.

RABOSSI, Fernando. Nas ruas de Ciudad del Este: Vidas e vendas num mercado de fronteira. Tese (Doutorado em Antropologia Social). Rio de Janeiro: Museu Nacional, 2004.

TISSIANO, Gabriel Merlini. Início e Dinâmica da Aglomaração Urbana de Fronteira: Foz do Iguaçu, Ciudad del Este e Puerto Iguazú. I Simpósio Nacional de Geografia e Gestão Territorial e XXXIV Semana de Geografia da Universidade Estadual de Londrina. 2018.

TRIVIÑOS, A. N. S. Introdução à pesquisa em ciências sociais: a pesquisa qualitativa em educação. São Paulo: Atlas, 1987. 